\title{
Countable stability of a weak solution of a parabolic differential-difference system with distributed parameters on the graph
}

\author{
V. V. Provotorov ${ }^{1}$, S. M. Sergeev ${ }^{2}$, V. N. Hoang ${ }^{1}$ \\ 1 Voronezh State University, 1, Universitetskaya pl., Voronezh, \\ 394006, Russian Federation \\ 2 Peter the Great St. Petersburg Polytechnic University, 29, Polytechnicheskaya ul., \\ St. Petersburg, 195251, Russian Federation
}

For citation: Provotorov V. V., Sergeev S. M., Hoang V. N. Countable stability of a weak solution of a parabolic differential-difference system with distributed parameters on the graph. Vestnik of Saint Petersburg University. Applied Mathematics. Computer Science. Control Processes, 2020, vol. 16, iss. 4, pp. 402-414. https://doi.org/10.21638/11701/spbu10.2020.405

The article proposes an analog of E. Rothe's method (semi-discretization with respect to the time variable) for construction convergent different schemes when analyzing the countable stability of a weak solution of an initial boundary value problem of the parabolic type with distributed parameters on a graph in the class of summable functions. The proposed method leads to the study of the input initial boundary value problem to analyze the boundary value problem in a weak setting for elliptical type equations with distributed parameters on the graph. By virtue of the specifics of this method, the stability of a weak solution is understood in terms of the spectral criterion of stability (Neumann's countable stability), which establishes the stability of the solution with respect to each harmonic of the generalized Fourier series of a weak solution or a segment of this series. Thus, there is another possibility indicated, in addition to the Faedo-Galerkin method, for constructing approaches to the desired solution of the initial boundary value problem, to analyze its stability and the way to prove the theorem of the existence of a weak solution to the input problem. The approach is applied to finding sufficient conditions for the countable stability of weak solutions to other initial boundary value problems with more general boundary conditions - in which elliptical equations are considered with the boundary conditions of the second or third type. Further analysis is possible to find the conditions under which Lyapunov stability is established. The approach can be used to analyze the optimal control problems, as well as the problems of stabilization and stability of differential systems with delay. Presented method of finite difference opens new ways for approximating the states of a parabolic system, analyzing their stability in the numerical implementation and algorithmization of optimal control problems.

Keywords: parabolic differential-difference system, distributed parameters on the graph, weak solution, countable stability.

1. Introduction. The paper provides a fairly sufficiently total approach of using ideas of the method of finite difference and some principles of construction converging different schemes when analyzing initial boundary value problems with distributed parameters on the graph in the class of summable up functions. The essence of the approach is not new - it is based on the method of E. Rote (1930), named in scientific literature by the method of semi-digitization (see, for example, [1]). This approach has been realized and proved in connection with the classic domains of spatial variable change [1, 2]. Further fundamental results of the study on the solvability of initial boundary value problems in network-like domains [3-5] allowed to transfer the ideas and results of $[1,2]$ without much difficulty in the case of parabolic equations with distributed parameters on the graph.

(C) Санкт-Петербургский государственный университет, 2020 
Below is a analogy of the Rote method [2, p. 189] which essentially reduce the analysis of the input initial boundary value problem to the study of the boundary value problem for elliptical type equations with distributed parameters on the graph. Thus, there is another possibility $[1,2,6]$, besides the Faedo-Galerkin method, to construction approaches to the desired solution of the initial boundary value problem, to analyze its stability and the way to prove the theorem of the existence of a weak solution to the input problem. The approach is applied to finding sufficient conditions for the stability of weak solutions to other initial boundary value problems with more total boundary conditions - in which elliptical equations are considered with the boundary conditions of the second or third type. The solvability of such problems is proved similarly to the reasoning for the problem with the boundary conditions of the first type.

2. Notations, concepts and basic statements. In the represented work uses concepts and notations accepted in the works $[6-10]: \Gamma$ is bounded oriented geometric graph with edges $\gamma$ parameterized segment $[0,1] ; \partial \Gamma$ and $J(\Gamma)$ are many boundary $\zeta$ and interior $\xi$ nodes of the graph, respectively; $\Gamma_{0}$ is join all the edges of the graph $\Gamma$ that do not contain endpoints; $\Gamma_{t}=\Gamma_{0} \times(0, t)\left(\gamma_{t}=\gamma_{0} \times(0, t)\right), \partial \Gamma_{t}=\partial \Gamma \times(0, t)(t \in(0, T]$, $T<\infty$ is arbitrary fixed constant).

In the course of the work the Lebesgue integral is used by $\Gamma$ or $\Gamma_{t}: \int_{\Gamma} f(x) d x=$ $\sum_{\gamma} \int_{\gamma} f(x)_{\gamma} d x$ or $\int_{\Gamma_{t}} f(x, t) d x d t=\sum_{\gamma} \int_{\gamma_{t}} f(x, t)_{\gamma} d x d t, f(\cdot)_{\gamma}$ is narrowing the function $f(\cdot)$ to the edge $\gamma$.

Necessary spaces and sets: $C^{1}[\Gamma]$ is space of continuous and differentiable on $\Gamma$ functions (derivative at the endpoints of the ribs is understood as one-sided), $L_{p}(\Gamma)$ $(p=1,2)$ is the Banach space of measurable on $\Gamma_{0}$ functions summarized with a $p$ degree (similar to space $\left.L_{p}\left(\Gamma_{T}\right)\right) ; L_{2,1}\left(\Gamma_{T}\right)$ is the space of function from $L_{1}\left(\Gamma_{T}\right)$ with the norm, defined by the ratio $\|u\|_{L_{2,1}\left(\Gamma_{T}\right)}=\int_{0}^{T}\left(\int_{\Gamma} u^{2}(x, t) d x\right)^{1 / 2} d t ; W_{2}^{1}(\Gamma)$ is the space of functions from $L_{2}(\Gamma)$ having a generalized first order derivative also from $L_{2}(\Gamma) ; W_{2}^{1,0}\left(\Gamma_{T}\right)$ is the space functions from $L_{2}\left(\Gamma_{T}\right)$ having a generalized first order derivative by $x$ belonging $L_{2}\left(\Gamma_{T}\right)$ (similarly entered the space $W_{2}^{1}\left(\Gamma_{T}\right)$ ).

Below is the difference-differential analogue of the parabolic equation

$$
\frac{\partial y(x, t)}{\partial t}-\frac{\partial}{\partial x}\left(a(x) \frac{\partial y(x, t)}{\partial x}\right)+b(x) y(x, t)=f(x, t), \quad x, t \in \Gamma_{T},
$$

with measurable bounded on $\Gamma_{0}$ functions $a(x), b(x)$ summable with the square:

$$
0<a_{*} \leqslant a(x) \leqslant a^{*},|b(x)| \leqslant \beta, x \in \Gamma_{0} .
$$

Introduce space states of the parabolic system and auxiliary spaces (see $[6,8,9]$ ). To do this in space $W_{2}^{1}(\Gamma)$ consider the bilinear form

$$
\ell(\mu, \nu)=\int_{\Gamma}\left(a(x) \frac{d \mu(x)}{d x} \frac{d \nu(x)}{d x}+b(x) \mu(x) \nu(x)\right) d x .
$$

The following statement to take place [11].

Lemma 1. Let fulfill conditions (2) and function $u(x) \in W_{2}^{1}(\Gamma)$ is such that $\ell(u, \nu)-$ $\int_{\Gamma} f(x) \eta(x) d x=0$ for any $\eta(x) \in W_{2}^{1}(\Gamma), f(x) \in L_{2}(\Gamma)$ is fixed function. Then for any edge $\gamma \subset \Gamma$ narrowing $a(x)_{\gamma} \frac{d u(x)_{\gamma}}{d x}$ continuously at the endpoints of the edge $\gamma$. 
Let's designate through $\Omega_{a}(\Gamma)$ a set of functions $u(x) \in C^{1}[\Gamma]$ that meet the conditions of Lemma 1 and ratios

$$
\sum_{\gamma \in R(\xi)} a(1)_{\gamma} \frac{d u(1)_{\gamma}}{d x}=\sum_{\gamma \in r(\xi)} a(0)_{\gamma} \frac{d u(0)_{\gamma}}{d x}
$$

in all the nodes $\xi \in J(\Gamma)$ (here $R(\xi)$ and $r(\xi)$ are sets of edges $\gamma$, respectively oriented "to node $\xi$ " and "from node $\xi$ "). The closing of the set $\Omega_{a}(\Gamma)$ in norm $W_{2}^{1}(\Gamma)$ relabel $W^{1}(a, \Gamma)$. In addition, if we assume that the functions $u(x) \in \Omega_{a}(\Gamma)$ satisfy the boundary condition $\left.u(x)\right|_{\partial \Gamma}=0$, then we will get space $W_{0}^{1}(a, \Gamma)$.

Next, let's designate through $W_{0}^{1,0}\left(a, \Gamma_{T}\right)$ the closure in the norma $W_{2}^{1,0}\left(\Gamma_{T}\right)$ the set of differentiable functions $\Omega\left(\Gamma_{T}\right)$, equal to zero near the boundary $\partial \Gamma_{T}$ and satisfying ratios

$$
\sum_{\gamma \in R(\xi)} a(1)_{\gamma} \frac{\partial u(1, t)_{\gamma}}{\partial x}=\sum_{\gamma \in r(\xi)} a(0)_{\gamma} \frac{\partial u(0, t)_{\gamma}}{\partial x}
$$

for all nodes $\xi \in J(\Gamma)$ and for any $t \in[0, T]$. Analogously let's introduce space $W_{0}^{1}\left(a, \Gamma_{T}\right)$ as the closure in the norma $W_{2}^{1}\left(\Gamma_{T}\right)$ set of functions $\Omega\left(\Gamma_{T}\right)$.

The space $W_{0}^{1,0}\left(a, \Gamma_{T}\right)$ describes many states $y(x, t)$ of the parabolic system (1), $W_{0}^{1}\left(a, \Gamma_{T}\right)$ is auxiliary space.

For functions $y(x, t) \in W_{0}^{1,0}\left(a, \Gamma_{T}\right)$ we consider equation (1) with initial and boundary conditions

$$
\left.y\right|_{t=0}=\varphi(x) \in L_{2}(\Gamma),\left.\quad y\right|_{x \in \partial \Gamma_{T}}=0 ;
$$

the first equality in (3) have meaning sense and is understood almost everywhere.

Remark 1. In the paper in detail be considered the first initial boundary value problem (1), (3) (the boundary condition of Dirichlet in ratios (3)), for the rest types of boundary conditions given the necessary comment.

Below are the subsidiary statements in space $W_{0}^{1,0}\left(a, \Gamma_{T}\right)$ and the main fragments of their evidence, the full evidence is given in the work [6].

Definition 1. A weak solution to the initial boundary value problem (1), (3) of class $W_{2}^{1,0}\left(\Gamma_{T}\right)$ is called a function $y(x, t) \in W_{0}^{1,0}\left(a, \Gamma_{T}\right)$ that satisfies the integral identity

$$
-\int_{\Gamma_{T}} y(x, t) \frac{\partial \eta(x, t)}{\partial t} d x d t+\ell_{T}(y, \eta)=\int_{\Gamma} \varphi(x) \eta(x, 0) d x+\int_{\Gamma_{T}} f(x, t) \eta(x, t) d x d t
$$

for any $\eta(x, t) \in W_{0}^{1}\left(a, \Gamma_{T}\right)$ that is zero at $t=T$. Here $\ell_{T}(y, \eta)$ is bilinear form, defined by the ratio

$$
\ell_{T}(y, \eta)=\int_{\Gamma_{T}}\left(a(x) \frac{\partial y(x, t)}{\partial x} \frac{\partial \eta(x, t)}{\partial x}+b(x) y(x, t) \eta(x, t)\right) d x d t
$$

In proving the solvability of the problem (1), (3) in space $W_{0}^{1,0}\left(a, \Gamma_{T}\right)$ is used a special basis of space $W_{0}^{1}(a, \Gamma)$, that is a system of generalized eigenfunctions of the boundary value problem

$$
-\frac{d}{d x}\left(a(x) \frac{d u(x)}{d x}\right)+b(x) u(x)=\lambda u(x),\left.u(x)\right|_{\partial \Gamma}=0
$$

in class $W^{1}(a, \Gamma)$ [11-13]. This problem is to find many such numbers (eigenvalues of the boundary value problem (5)), each of which corresponds to at least one nontrivial generalized solution $u(x) \in W_{0}^{1}(a, \Gamma)$ (generalized eigenfunction) that satisfies an integral 
identity $\ell(u, \eta)=\lambda(u, \eta)$ for any function $\eta(x) \in W_{0}^{1}(a, \Gamma)$ (here and everywhere below through $(\cdot, \cdot)$ designated the scalar product in $L_{2}(\Gamma)$ or $\left.L_{2}\left(\Gamma_{T}\right)\right)$. The following statement is true.

Lemma 2. Let the assumptions (2) be fulfilled. Then the spectral problem (5) has an denumerable set of real eigenvalues $\left\{\lambda_{i}\right\}_{i \geqslant 1}$ (numbered in ascending order, with regard for their multiplicity) with a limit point on infinity (eigenvalues $\lambda_{i}$ are positive, with the exception of maybe the final number of the first). The system of generalized eigenfunctions $\left\{u_{i}(x)\right\}_{i \geqslant 1}$ forms a basis in $W_{0}^{1}(a, \Gamma)$ and $L_{2}(\Gamma)$, orth-normalized in $W_{0}^{1}(a, \Gamma)$.

Remark 2. If $b(x) \geqslant 0$ in (2), as is the case in applications, then all the eigenvalues of the spectral problem (5) are nonnegative.

Theorem 1. For any $f(x) \in L_{2,1}\left(\Gamma_{T}\right), \varphi(x) \in L_{2}(\Gamma)$ and for any $0<T<\infty$ the initial boundary value problem (1), (3) is weak solvable in space $W_{0}^{1,0}\left(a, \Gamma_{T}\right)$.

With proof of theorem we construct the Faedo-Galerkin's approximations on the basis $\left\{u_{i}(x)\right\}_{i \geqslant 1}$ : the approximate solutions $y^{N}(x, t)$ (natural $N$ is fixed) of problem (1), (3) have form $y^{N}(x, t)=\sum_{i=1}^{N} c_{i}^{N}(t) u_{i}(x)$, where $c_{i}^{N}(t)$ are absolutely continuous on [0,T] functions $\left(c_{i}^{\prime}(t) \in L_{2}(0, T)\right)$, defined from the system

$$
\begin{gathered}
\left(\frac{\partial y^{N}}{\partial t}, u_{i}\right)+\int_{\Gamma}\left(a(x) \frac{\partial y^{N}(x, t)}{\partial x} \frac{d u_{i}(x)}{d x}+b(x) y^{N}(x, t) u_{i}(x)\right) d x=\left(f, u_{i}\right), \\
c_{i}^{N}(0)=\left(\varphi, u_{i}\right), i=\overline{1, N} .
\end{gathered}
$$

Further reasoning based on a priori estimates of norm of weak solutions (1), (3) and construction the subsequence $\left\{y^{N_{k}}\right\}_{k \geqslant 1}$ of sequence $\left\{y^{N}\right\}_{N \geqslant 1}$, weakly converge to solution $y(x, t) \in W_{0}^{1,0}\left(a, \Gamma_{T}\right)$ in a norm of $W_{0}^{1,0}\left(\Gamma_{T}\right)$ (weak compactness $\left\{y^{N_{k}}\right\}_{k \geqslant 1}$ ). Namely, it is shown that for a approximate solution $y^{N}(x, t)$ is inequality

$$
\left\|y^{N}\right\|_{2, \Gamma_{t}} \leqslant C(t)\left(\left\|y^{N}(x, 0)\right\|_{L_{2}(\Gamma)}+2\|f\|_{L_{2,1}\left(\Gamma_{t}\right)}\right)
$$

for any $t \in[0, T]$, where $\|\cdot\|_{2, \Gamma_{t}}$ is a norm of $W^{1,0}\left(\Gamma_{t}\right)$, the function $C(t)$ is limited to $t \in[0, T]\left(C(t) \leqslant C^{*}, 0<C^{*}<\infty\right)$, not depend on $N$, is determined by the value $T$ and permanent $a^{*}, \beta$. From this inequality, taking into account the ratio $c_{i}^{N}(0)=\left(\varphi, u_{i}\right)$ $(i=\overline{1, N})$ and by virtue of inequalities

$$
\left\|y^{N}(x, 0)\right\|_{L_{2}(\Gamma)}=\left\|\sum_{i=1}^{N}\left(\varphi, u_{i}\right) u_{i}(x)\right\| \leqslant \sqrt{\sum_{i=1}^{N}\left|\left(\varphi, u_{i}\right)\right|} \leqslant\|\varphi\|_{L_{2}(\Gamma)}
$$

$\left(\|\cdot\|\right.$ is Euclidean norm: $\left.\|\omega\|=\sqrt{\sum_{i=1}^{N} \omega_{i}^{2}}\right)$ it should be

$$
\left\|y^{N}\right\|_{2, \Gamma_{t}} \leqslant C(t)\left(\|\varphi\|_{L_{2}(\Gamma)}+2\|f\|_{L_{2,1}\left(\Gamma_{t}\right)}\right)
$$

that means independent of $N$ estimate $\left\|y^{N}\right\|_{2, \Gamma_{t}} \leqslant C(C>0)$.

The latter means: from the sequence $\left\{y^{N}\right\}_{N \geqslant 1}$ with limited totality elements $y^{N}$ can be distinguish the subsequence $\left\{y^{N_{k}}\right\}_{k \geqslant 1}$, that converge weakly to certain element $y \in W^{1,0}\left(a, \Gamma_{T}\right)$ at a norm $W_{0}^{1,0}\left(\Gamma_{T}\right)\left(\left\{y^{N_{k}}\right\}_{k \geqslant 1}\right.$ converge weakly to $y$ together with $\frac{\partial y^{N_{k}}}{\partial x}$ at a norm $\left.L_{2}\left(\Gamma_{T}\right)\right)$. As a result of the consequent reasoning become clear that 
the all sequence $\left\{y^{N}\right\}_{N \geqslant 1}$ is weakly converges to an element $y \in W_{0}^{1,0}\left(a, \Gamma_{T}\right.$ ) (so as $\left.\|\cdot\|_{W^{1,0}\left(\Gamma_{T}\right)} \leqslant\|\cdot\|_{2, \Gamma_{T}}\right)$. Element $y(x, t)$ is a weak solution problem (1), (4).

Theorem 2. If the conditions of the theorem 1, then initial boundary value problem (1), (3) has only a weak solution in the space $W_{0}^{1,0}\left(a, \Gamma_{T}\right)$ for any $0<T<\infty$.

Proof of uniqueness by virtue of linearity problem (1), (3) is the standard way: assumes the existence of two different solutions $y_{1}(x, t), y_{2}(x, t)$ of class $W_{0}^{1,0}\left(a, \Gamma_{T}\right)$. Where and from (6) it should be inequality $\|y\|_{2, \Gamma_{T}} \leqslant 0\left(y(x, t)=y_{1}(x, t)-y_{2}(x, t)\right)$ for any $T>0$, and that means, coincidence solutions $y_{1}(x, t), y_{2}(x, t)$ in space $W_{0}^{1,0}\left(a, \Gamma_{T}\right)\left(y_{1}(x, t)=y_{2}(x, t)\right.$ almost everywhere).

Corollary. A weak solution of initial boundary value problem (1), (3) continuously depends on the source data $f(x, t)$ and $\varphi(x)$. Thus shows the correctness of Hadamard initial boundary value problem $(1),(3)$ in the space $W_{0}^{1,0}\left(a, \Gamma_{T}\right)$ for any $0<T<\infty$.

Remark 3. Statements of Theorems 1 and 2 are preserved under substitution $[0, T]$ on $\left[t_{0}, T\right]\left(t_{0}>0\right)$, the initial condition in the ratio (3) is replaced by $\left.y\right|_{t=t_{0}}=\varphi(x)$.

Remark 4. Boundary condition in (3) can be non-homogeneity:

$$
\left.y(x, t)\right|_{x \in \partial \Gamma}=\phi(x, t) .
$$

Proof of Theorems 1 and 2 in this case literally repeat the above reasonings. For this as a preliminary introduces a new unknown function $\widetilde{y}(x, t)=y(x, t)-\Phi(x, t)$ (here $\Phi(x, t)$ is a arbitrary function of $L_{2}\left(\Gamma_{T}\right)$, having generalized derivative $\frac{\partial \Phi}{\partial x} \in L_{2}\left(\Gamma_{T}\right)$ and satisfying (almost everywhere) non-homogeneity boundary condition). The integral identities in definition 1 be changed respectively.

3. Differential-difference system. Below make use of analog of the Rote method [2, p. 189], which essentially reduce the analysis of initial boundary value problem (1), (3) to the study of the boundary value problem for elliptical type equations with distributed parameters on the graph $\Gamma$. In space $W_{0}^{1,0}\left(a, \Gamma_{T}\right)$ consider the equation (1) and dissect the domain $\Gamma_{T}$ planes $t=k \tau, k=0,1,2, \ldots, M, \tau=\frac{T}{M}$, in addition denote by $\Gamma_{T}^{k}$ section $\Gamma_{T}$ the plane $t=k \tau$. Equation (1) will replace differential-difference

$$
\begin{gathered}
\frac{1}{\tau}(u(k)-u(k-1))-\frac{d}{d x}\left(a(x) \frac{d u(k)}{d x}\right)+b(x) u(k)=f_{\tau}(k) \\
(k=1,2, \ldots, M),
\end{gathered}
$$

where

$$
f_{\tau}(k)=f_{\tau}(x, k)=\frac{1}{\tau} \int_{(k-1) \tau}^{k \tau} f(x, t) d t \in L_{2}(\Gamma) .
$$

Functions $u(k)(k=1,2, \ldots, M)$ will define as a solution to the equation system $(7)$ that meets the conditions

$$
u(0)=\varphi(x),\left.\quad u(k)\right|_{x \in \partial \Gamma}=0(k=1,2, \ldots, M) .
$$

Ratios (7), (8) is the boundary value problem for the system of elliptical equations (7).

Remark 5. Ratios (7), (8) are analogous to the implicitly difference scheme of the first order of approximation on the time variable $t$ for the initial boundary value problem (1), (3), set in space $W_{0}^{1,0}\left(a, \Gamma_{T}\right)$, with an elliptical operator $-\frac{d}{d x}\left(a(x) \frac{d u}{d x}\right)+b(x) u, u \in$ $W_{0}^{1}(a, \Gamma)$.

Definition 2. A weak solution to a boundary value problem (7), (8) is called functions $u(k)=W_{0}^{1}(a, \Gamma)(k=0,1,2, \ldots, M), u(0)=\varphi(x)\left(\varphi(x) \in L_{2}(\Gamma)\right)$, satisfying an integral identity 


$$
\begin{gathered}
\int_{\Gamma} u(k)_{t} \eta(x) d x+\ell(u(k), \eta)=\int_{\Gamma} f_{\tau}(k) \eta(x) d x \\
(k=1,2, \ldots, M)
\end{gathered}
$$

for any $\eta(x) \in W_{0}^{1}(a, \Gamma)$; equality $u(0)=\varphi(x)$ is understood almost everywhere,

$$
u(k)_{t}=u(x, k)_{t}=\frac{1}{\tau}(u(k)-u(k-1)) .
$$

We will establish the correctness of the statements, similar to presented in Theorems 1 and 2 .

Theorem 3. The following statements take place:

1. For any $k_{0} \geqslant 0$ and any $\varphi(x) \in L_{2}(\Gamma)$ weak solution $u(k)$ is uniquely defined at $k_{0} \leqslant k \leqslant M\left(k_{0}<M<\infty\right)$.

2. A weak solution of the initial boundary value problem (1), (3) is the limit of functions $u(k)$, calculated from ratios $(7),(8)$.

P r o o f. Beforehand we will obtain an $u(k)$ a priori estimate that not dependent on $\tau$. Out of the ratio $u(k-1)^{2}=\left(u(k)-\tau u(k)_{t}\right)^{2}=u(k)^{2}+\tau^{2} u(k)_{t}^{2}-2 \tau u(k) u(k)_{t}$ follow relation

$$
2 \tau u(k) u(k)_{t}=u(k)^{2}+\tau^{2}\left(u(k)_{t}\right)^{2}-u(k-1)^{2} .
$$

Let as take in the ratio $(9) \eta(x)=2 \tau u(k)$ and granting (10), as well as the lower boundary $a_{*}$ for $a(x)$ (see $\left.(2)\right)$ get inequality

$$
\begin{gathered}
\int_{\Gamma} u(k)^{2} d x-\int_{\Gamma} u(k-1)^{2} d x+\tau^{2} \int_{\Gamma}\left(u(k)_{t}\right)^{2} d x+2 a_{*} \tau \int_{\Gamma}\left(\frac{d u(k)}{d x}\right)^{2} d x \leqslant \\
\leqslant-2 \tau \int_{\Gamma} b(x) u(k)^{2} d x+2 \tau \int_{\Gamma} f_{\tau}(k) u(k) d x,
\end{gathered}
$$

from here (everywhere below through $\|\cdot\|_{2, \Gamma}$ the marked norm in space $W_{2}^{1}(\Gamma)$ )

$$
\begin{gathered}
\|u(k)\|_{2, \Gamma}^{2}-\|u(k-1)\|_{2, \Gamma}^{2}+\tau^{2}\left\|u(k)_{t}\right\|_{2, \Gamma}^{2}+2 a_{*} \tau\left\|\frac{d u(k)}{d x}\right\|^{2} \leqslant \\
\leqslant-2 \tau \int_{\Gamma} b(x) u(k)^{2} d x+2 \tau \int_{\Gamma} f_{\tau}(k) u(k) d x \leqslant \\
\leqslant 2 \beta \tau\|u(k)\|_{2, \Gamma}^{2}+2 \tau\left\|f_{\tau}(k)\right\|_{2, \Gamma}\|u(k)\|_{2, \Gamma} .
\end{gathered}
$$

As a result, with $k=1,2, \ldots, M$,

$$
\begin{gathered}
\|u(k)\|_{2, \Gamma}^{2}-\|u(k-1)\|_{2, \Gamma}^{2}+\tau^{2}\left\|u(k)_{t}\right\|_{2, \Gamma}^{2}+2 a_{*} \tau\left\|\frac{d u(k)}{d x}\right\|^{2} \leqslant \\
\leqslant \varrho \tau\|u(k)\|_{2, \Gamma}^{2}+2 \tau\left\|f_{\tau}(k)\right\|_{2, \Gamma}\|u(k)\|_{2, \Gamma},
\end{gathered}
$$

where $\varrho=2 \beta$. The latest inequality ensue from

$$
\|u(k)\|_{2, \Gamma}^{2}-\|u(k-1)\|_{2, \Gamma}^{2} \leqslant \varrho \tau\|u(k)\|_{2, \Gamma}^{2}+2 \tau\left\|f_{\tau}(k)\right\|_{2, \Gamma}\|u(k)\|_{2, \Gamma} .
$$

1. Let $\|u(k)\|_{2, \Gamma}+\|u(k-1)\|_{2, \Gamma}>0$, then divide both parts of inequality (12) on $\|u(k)\|_{2, \Gamma}+\|u(k-1)\|_{2, \Gamma}$ and taking into account

$$
\frac{\|u(k)\|_{2, \Gamma}}{\|u(k)\|_{2, \Gamma}+\|u(k-1)\|_{2, \Gamma}} \leqslant 1
$$

come to an estimate

$$
\|u(k)\|_{2, \Gamma} \leqslant \frac{1}{1-\varrho \tau}\|u(k-1)\|_{2, \Gamma}+\frac{2 \tau}{1-\varrho \tau}\left\|f_{\tau}(k)\right\|_{2, \Gamma},
$$

when $\tau<\frac{1}{2 \varrho}$.

Вестник СПбГУ. Прикладная математика. Информатика... 2020. Т. 16. Вып. 4 
2. Let $\|u(k)\|_{2, \Gamma}+\|u(k-1)\|_{2, \Gamma}=0$, then from the ratio (12) follows $0 \leqslant \varrho \tau\|u(k)\|_{2, \Gamma}+$ $2 \tau\left\|f_{\tau}(k)\right\|_{2, \Gamma}$, that means

$$
\|u(k)\|_{2, \Gamma} \leqslant \varrho \tau\|u(k)\|_{2, \Gamma}-\|u(k-1)\|_{2, \Gamma}+2 \tau\left\|f_{\tau}(k)\right\|_{2, \Gamma},
$$

that again leads to an estimate (13).

Given the recursively of the estimate (13), we get

$$
\begin{gathered}
\|u(k)\|_{2, \Gamma} \leqslant \frac{1}{(1-\varrho \tau)^{k}}\|u(0)\|_{2, \Gamma}+2 \tau \sum_{s=1}^{k} \frac{1}{(1-\varrho \tau)^{k-s+1}}\left\|f_{\tau}(s)\right\|_{2, \Gamma} \leqslant \\
\leqslant \frac{1}{(1-\varrho \tau)^{k}}\left(\|u(0)\|_{2, \Gamma}+2 \tau \sum_{s=1}^{k}\left\|f_{\tau}(s)\right\|_{2, \Gamma}\right) \leqslant \\
\leqslant e^{2 \varrho T}\left(\|u(0)\|_{2, \Gamma}+2\left\|f_{\tau}(k)\right\|_{2,1, \Gamma_{T}}\right) .
\end{gathered}
$$

Here $\left\|f_{\tau}(k)\right\|_{2,1, \Gamma_{T}}=\tau \sum_{s=1}^{k}\left\|f_{\tau}(s)\right\|_{2, \Gamma}$, the latest inequality follows from the ratios $\frac{\varrho \tau}{1-\varrho \tau} k \leqslant$ $\frac{\varrho T}{1-\varrho \tau} \leqslant 2 \varrho T$ at $\tau<\frac{1}{2 \varrho}$ and $\frac{1}{(1-\varrho \tau)^{k}} \leqslant e^{2 \varrho T}$. Thus, a estimate has been obtained

$$
\|u(k)\|_{2, \Gamma} \leqslant e^{2 \varrho T}\left(\|u(0)\|_{2, \Gamma}+2\left\|f_{\tau}(k)\right\|_{2,1, \Gamma_{T}}\right) .
$$

Further, summing up the inequality (11) by $k$ from 1 to $m \leqslant M$ and using the estimate (14), we come to

$$
\begin{gathered}
\|u(m)\|_{2, \Gamma}^{2}+2 a_{*} \tau \sum_{k=1}^{m}\left\|\frac{d u(k)}{d x}\right\|^{2}+\tau^{2} \sum_{k=1}^{m}\left\|u(k)_{t}\right\|_{2, \Gamma}^{2} \leqslant \\
\leqslant c_{1}\left(\|\varphi\|_{2, \Gamma}^{2}+\left\|f_{\tau}(m)\right\|_{2,1, \Gamma_{T}}^{2}\right), \quad m=\overline{1, M},
\end{gathered}
$$

where $c_{1}$ it depends only on $a_{*}, \beta$ and $T ;\left\|f_{\tau}(m)\right\|_{2,1, \Gamma_{T}} \leqslant\|f\|_{L_{2,1}\left(\Gamma_{T}\right)}$. Going over in the resulting inequality to the limit, when $M \rightarrow \infty$ we get a limited totality sequence $\{u(m)\} \subset W_{0}^{1}(a, \Gamma)\left(\|u(m)\|_{2, \Gamma} \leqslant \widetilde{c}_{1}, m=1,2, \ldots\right)$, from which you can choose a subsequence $\left\{u\left(m_{i}\right)\right\}$, weakly convergent to a certain element $u(x) \in W_{0}^{1}(a, \Gamma)$. The first statement of the theorem is proven.

Let's show the correctness of the second statement. Introduce piecewise constant interpolations $\widetilde{u}(x, t)$ by $t$ for $u(k)$, namely: $\widetilde{u}(x, t)=u(k)$, when $t \in((k-1) \tau, k \tau], k=$ $\overline{1, M}$. It is clear that $\widetilde{u}(x, t)$ will be elements of space $W_{0}^{1,0}\left(a, \Gamma_{T}\right)$ and for them by virtue of (15) take place estimate

$$
\|\widetilde{u}\|_{2, \Gamma_{T}}+\left\|\frac{\partial \widetilde{u}}{\partial x}\right\|_{2, \Gamma_{T}} \leqslant c_{2},
$$

constant $c_{2}$ not depend on $\tau$. Going over in (16) to the limit when $M \rightarrow \infty$ we get a limited totality sequence $\{\widetilde{u}\} \subset W_{0}^{1,0}\left(a, \Gamma_{T}\right)$ from which you can choose a subsequence, weakly convergent to a certain element $u(x, t) \in W_{0}^{1,0}\left(a, \Gamma_{T}\right)$. Let's show that the function $u(x, t)$ satisfies the integral identity (4), i. e. is a weak solution from $W_{0}^{1,0}\left(a, \Gamma_{T}\right)$ of the initial boundary value problem (1), (3). Set this identity for fairly smooth functions $\eta(x, t)$, equal to zero on $\partial \Gamma_{T}$ and at $t=T$ : let's $\eta(x, t) \in C^{1}\left(\Gamma_{T+\tau}\right)$, it's zero on $\partial \Gamma_{T}$ and on $t=T$. We construct for $\eta(x, t)$ averaging $\eta(k)=\eta(x, k \tau)$, interpolations $\widetilde{\eta}(x, t)$ and $\widetilde{\eta}(x, t)_{t}\left(\eta(k)_{t}=\frac{1}{\tau}(\eta(k+1)-\eta(k))\right.$. It's easily to verify that interpolations $\widetilde{\eta}, \frac{\partial \widetilde{\eta}}{\partial x}, \widetilde{\eta}_{t}$ on $\Gamma_{T}$ uniformly converge to functions $\eta(x, t), \frac{\partial \eta(x, t)}{\partial x}$ and $\frac{\partial \eta(x, t)}{\partial t}$, respectively, in addition $\widetilde{\eta}(x, t)=0, t \in[T, T+\tau]$. 
Under $\eta(k)_{t}=\frac{1}{\tau}(\eta(k+1)-\eta(k))$ correctly

$$
\tau \sum_{k=1}^{M} u(k)_{t} \eta(k)=-\tau \sum_{k=1}^{M} u(k) \eta(k)_{t}-u(0) \eta(1) .
$$

Summing the identities $(9)$ at $\eta(x)=\tau \eta(k)$ over $k$ from 1 until $M$ and taking into account $(17)$, as well as $\eta(M)=\eta(M+1)=0$, get

$$
\begin{gathered}
-\tau \sum_{k=1}^{M} \int_{\Gamma} u(k) \eta(k)_{t} d x-\int_{\Gamma} \varphi(x) \eta(1) d x+\tau \sum_{k=1}^{M} \ell(u(k), \eta(k))= \\
=\tau \sum_{k=1}^{M}\left(f_{\tau}(k), \eta(k)\right)
\end{gathered}
$$

or

$$
\begin{gathered}
-\int_{\Gamma_{T}} \widetilde{u}(x, t) \widetilde{\eta}(x, t)_{t} d x d t+\ell_{T}(\widetilde{u}, \widetilde{\eta})-\int_{\Gamma} \varphi(x) \eta(1) d x= \\
=\int_{\Gamma_{T}} f(x, t), \widetilde{\eta}(x, t) d x d t .
\end{gathered}
$$

In the ratio (18), going over to the limit on the chosen above weakly convergent in $W_{0}^{1,0}\left(a, \Gamma_{T}\right)$ the subsequence of the sequence $\{\widetilde{u}(x, t)\} \quad\left(u(x, t) \in W_{0}^{1,0}\left(a, \Gamma_{T}\right)\right.$ is limit function), we get an integral identity (4), at means the function $u(x, t)$ is a weak solution of the initial boundary value problem (1), (3) of the space $W_{0}^{1,0}\left(a, \Gamma_{T}\right)$. By virtue of the uniqueness of solution $u(x, t)$ (Theorem 1) and the estimate (16) the whole sequence $\{\widetilde{u}(x, t)\}$ is weakly converged to $u(x, t)$. The theorem is fully proven.

Remark 6. The first statement of the theorem (essentially there is a method of finite difference) provides another possibility (except for the Faedo-Galerkin method, presented by the statement of the Theorem 1) of constructing approximations to the solution, along the way realizing (along with the second statement of the theorem) and proof of the theorem of the existence of the initial boundary value problem (1), (3). The approach used also applies to finding solutions to other initial boundary value problem. In them, the boundary conditions of the second or third type is added to the elliptical equations (7). The solvability of such problems is proved similar to reasoning for the problem (7), (8). Finally, both the Faedo-Galerkin method and the of finite difference method open the way to approximate the states of the system in numerical realization (construction algorithms) of the posed problems.

4. The countably stability of the differential-difference system of equations $(7),(8)$. We do not seek to a possible generality of define the concept of countably stability of the differential-difference equations or systems of equations, as we are interested in approaches to the analysis of the quality of the differential-difference system of equations (7), (8), approximating the initial boundary value problem (1), (3).

In the assumptions of section 3 , consider the differential-difference system of equations (7), (8) in a weak formulation (9). Let's introduce the following of Fourier series on the system $\left\{u_{i}(x)\right\}_{i \geqslant 1}$ (see Lemma 2 ):

$$
u(k)=\sum_{i} u^{i}(k) u_{i}(x), \quad f_{\tau}(k)=\sum_{i} f_{\tau}^{i}(k) u_{i}(x), \quad \varphi=\sum_{i} \varphi^{i} u_{i}(x),
$$

where $u^{i}(k)=\left(u(k), u_{i}\right), f_{\tau}^{i}(k)=\left(f_{\tau}(k), u_{i}\right), \varphi^{i}=\left(\varphi, u_{i}\right)$.

D. Neumann introduced the concept of countably stability of the difference schemes of evolutionary equations [14]. Below is an analogue of this concept, following the work of $[15$, p. 44]. 
Definition 3. Differential-difference system (7), (8) is called countably stability, if for each coefficient $u_{\tau}(k)$ of the Fourier series (19) take place inequality

$$
|u(k)| \leqslant C_{1 n}\left|\varphi^{n}\right|+C_{2 n}\left|f^{n}\right|,
$$

where constants $C_{1 i}, C_{2}$ are uniformly bounded at $0 \leqslant k \tau \leqslant T,\left|f^{n} i\right|=\max _{k=\overline{1, M}}\left|f_{\tau}^{i}(k)\right|$.

For $\eta(x)=u_{i}(x), i=1,2, \ldots$, get

$$
\begin{gathered}
u^{i}(k)-u^{i}(k-1)+\tau \lambda_{i} u^{i}(k)=\tau f_{\tau}^{i}(k-1), u^{i}(0)=\varphi^{i} \\
(k=1,2, \ldots, M),
\end{gathered}
$$

$f_{\tau}^{i}(k-1)$ it's chosen as $f^{i}\left(t_{k}\right): f^{i}\left(t_{k}\right)=\left(f\left(x, t_{k}\right), u_{i}(x)\right)$. The sequential exclusion of the unknown $u^{i}(j), j=1,2, \ldots, k$, reduce to a ratio

$$
\begin{gathered}
u^{i}(k)=r_{i}^{k} \varphi^{i}+\tau r_{i} \sum_{j} r_{i}^{k-i} f_{\tau}^{i}(j-1) \\
(k=1,2, \ldots, M),
\end{gathered}
$$

here $r_{i}=\left(1+\tau \lambda_{i}\right)^{-1}$. From here take place estimate

$$
\begin{gathered}
\left|u^{i}(k)\right| \leqslant\left|r_{i}\right|^{k}\left|\varphi^{i}\right|+\tau\left|r_{i}\right| \sum_{j}\left|r_{n}^{k-j}\right|\left|f_{\tau}^{i}(j-1)\right| \leqslant \\
\leqslant\left|r_{i}\right|^{k}\left|\varphi^{i}\right|+\tau\left|r_{i}\right| \frac{1-\left|r_{i}\right|^{k}}{1-\left|r_{i}\right|}\left|f^{i}\right|, \quad\left|f^{i}\right|=\max _{k=\overline{1, M}}\left|f_{\tau}^{i}(k)\right| \\
(k=1,2, \ldots, M) .
\end{gathered}
$$

As $0<r_{i}<1(i=1,2, \ldots)$ then $\left|r_{i}\right|^{k}<1$ and $\tau\left|r_{i}\right| \frac{1-\left|r_{i}\right|^{k}}{1-\left|r_{i}\right|}<\tau\left|r_{i}\right| \frac{1}{1-\left|r_{i}\right|}<T+\frac{1}{\lambda_{1}}$, it means, the coefficients of $\left|\varphi^{i}\right|$ and $\left|f^{i}\right|$ are uniformly bounded at any value $\tau>0$ and do not depend on $\tau, \varphi$ and $f$. This means that the spectral criterion of counting stability of definition 3 be fulfilled: differential-difference system (7), (8) is absolutely countably stability.

5. Example. We consider the example reduced in the work [10]. Let $\Gamma$ is a graph-star with edges $\gamma_{\ell}, \ell=1,2,3$, and a interior node $\xi$ (to simplify the formulas, let's assume that the edges $\gamma_{\ell}, \ell=1,2$, are parameterized by a segment $[0, \pi / 2], \gamma_{3}$ is parameterized by a segment $[\pi / 2, \pi])$. In space $W_{0}^{1,0}\left(a, \Gamma_{T}\right)$, consider the initial boundary value problem (1), (3) at $a(x)=1, b(x)=0$ and $f(x, t)=0$ :

$$
\frac{\partial y(x, t)}{\partial t}=\frac{\partial^{2} y(x, t)}{\partial x^{2}},\left.y\right|_{t=0}=\varphi(x), x \in \Gamma,\left.y\right|_{x \in \partial \Gamma_{T}}=0 .
$$

The weak solution $y(x, t) \in W_{0}^{1,0}\left(1, \Gamma_{T}\right)$ of problem $(20)$ is determined by identity

$$
-\int_{\Gamma_{T}} y(x, t) \frac{\partial \eta(x, t)}{\partial t} d x d t+\int_{\Gamma_{T}} \frac{\partial y(x, t)}{\partial t} \frac{\partial \eta(x, t)}{\partial t} d x d t=\int_{\Gamma} \varphi(x) \eta(x, 0) d x
$$

for any function $\eta(x, t) \in W_{0}^{1}\left(1, \Gamma_{T}\right)$ that is zero at $t=T$.

Let's define the differential-difference analog of the system (20) (see (7)) ratios

$$
\begin{gathered}
\frac{1}{\tau}(y(k)-y(k-1))-\frac{d^{2} y(k)}{d x^{2}}=0, k=1,2, \ldots, \\
y(0)=\varphi,\left.\quad y(k)\right|_{\partial \Gamma}=0, \\
y(k) \in W_{0}^{1}(a, \Gamma)(k=1,2, \ldots), \varphi(x) \in L_{2}(\Gamma) .
\end{gathered}
$$


Functions $y(k)(k=1,2, \ldots)$ are defined by virtue of recurrence ratios for integral identities

$$
(y(k)-y(k-1), \eta(x))+\tau\left(\frac{d y(k)}{d x}, \frac{d \eta}{d x}\right)=0 \quad \forall \eta(x) \in W_{0}^{1}(a, \Gamma), k=1,2, \ldots,
$$

here $y(0)=\varphi(x), x \in \Gamma$.

Easily to show [11-13], that the spectral problem (5) (under $a(x)=1, b(x)=0$ ) in the weak formulation defines a set of eigenvalues $\left\{\lambda_{i}\right\}_{i \geqslant 1}\left(\lambda_{i}=i^{2}\right)$ and system of generalized eigenfunctions $\left\{u_{i}\right\}_{i \geqslant 1}$, where eigenvalues when $i=2 j-1$ is prime numbers, when $i=2 j$ have multiplicity 2 , the corresponding generalized eigenfunctions are determined by the relations $(j=1,2, \ldots)$

$$
\begin{gathered}
u_{2 j-1}(x)=\left\{\begin{array}{l}
\cos (2 j-1)\left(x-\frac{\pi}{2}\right), x \in \gamma_{1}, \\
\cos (2 j-1)\left(x-\frac{\pi}{2}\right), x \in \gamma_{2}, \\
\cos (2 j-1)\left(x-\frac{\pi}{2}\right), x \in \gamma_{3},
\end{array}\right. \\
u_{2 j, 1}(x)=\left\{\begin{array}{c}
0, x \in \gamma_{1}, \\
\sin 2 j\left(x-\frac{\pi}{2}\right), x \in \gamma_{1}, \\
0, x \in \gamma_{2}, \\
\sin 2 j\left(x-\frac{\pi}{2}\right), x \in \gamma_{3},
\end{array} \quad u_{2 j, 2}(x)=\left\{\begin{array}{c}
\sin 2 j\left(x-\frac{\pi}{2}\right), x \in \gamma_{2}, \\
\sin 2 j\left(x-\frac{\pi}{2}\right), x \in \gamma_{3} .
\end{array}\right.\right.
\end{gathered}
$$

Let $\eta(x)=u_{i}(x)(i=1,2, \ldots)$ then the ratios connecting Fourier's coefficients $y^{i}(k)$, $\varphi^{i}$ of the elements $y(k), \varphi$ for each $i=1,2, \ldots$, take the form of

$$
y^{i}(k)-y^{i}(k-1)+\tau i^{2} y^{i}(k)=0, y^{i}(0)=\varphi^{i}, k=1,2, \ldots .
$$

From here $y^{i}(k)=\left(1+\tau i^{2}\right)^{-k} \varphi^{n}$ and for any $\tau>0$

$$
\left|y^{i}(k)\right| \leqslant \frac{1}{\left(1+\tau i^{2}\right)^{k}}\left|\varphi^{n}\right|, k=1,2, \ldots .
$$

The absolute countably stability of the differential-difference system is obvious. The last inequality have as a consequence stability of the system to norm $L_{2}(\Gamma)$ :

$$
\|y(k)\|_{L_{2}(\Gamma)} \leqslant\|\varphi\|_{L_{2}(\Gamma)}, k=1,2, \ldots .
$$

6. Conclusion. The work outlines an approach to the analysis of the differential system with distributed parameters on the graph, which, not using the Faedo-Galerkin method, establishes the theorem of the existence of a solution to the initial boundary value problem (1), (3) and at the same time gives you the opportunity to obtain the conditions of stability (countably stability) of the investigated problem. The proposed method can be used for solve other initial boundary value problems. In this case, the boundary conditions of the second or third types is added to the elliptical equations (7). Note also, the used approach it is not difficult to extend to the case when $\Gamma$ is a netlike domain of Euclidean space $\mathbb{R}^{n}(n \geqslant 2)$.

Further analysis is possible on the way to finding the conditions of the Lyapunov stability of problem (1), (3). The approach can be used to analyze the optimal control problems of [16-20], as well as the problems of stabilization and stability of differential systems with delay [21-27].

\section{References}

1. Lions J.-L. Nekotorye metody resheniya nelineinykh kraevykh zadach [Some methods of solving non-linear boundary value problems]. Moscow, Mir Publ., 1972, 587 p. (In Russian) 
2. Ladyzhenskaya O. A. Kraevye zadachi matematicheskoi fiziki [Boundary value problems of mathematical physics]. Moscow, Nauka Publ., 1973, 407 p. (In Russian)

3. Provotorov V. V., Sergeev S. M., Part A. A. Solvability of hyperbolic systems with distributed parameters on the graph in the weak formulation. Vestnik of Saint Petersburg University. Applied Mathematics. Computer Science. Control Processes, 2019, vol. 15, iss. 1, pp. $107-117$. https://doi.org/10.21638/11702/spbu10.2019.2003

4. Provotorov V. V., Ryazhskikh V. I., Gnilitskaya Yu. A. Unique weak solvability of nonlinear initial boundary value problem with distributed parameters in the netlike domain. Vestnik of Saint Petersburg University. Applied Mathematics. Computer Science. Control Processes, 2017, vol. 13, iss. 3, pp. $264-277$. https://doi.org/10.21638/11701/spbu10.2017.304

5. Artemov M. A., Baranovskii E. S., Zhabko A. P., Provotorov V. V. On a 3D model of nonisothermal flows in a pipeline network. Journal of Physics. Conference Series, 2019, vol. 1203, Article ID 012094. https://doi.org/10.1088/1742-6596/1203/1/012094

6. Provotorov V. V., Provotorova E. N. Sintez optimal'nogo granichnogo upravlenija parabolicheskoi sistemy s zapazdyvaniem i raspredekennemi parametrami na grafe [Synthesis of optimal boundary control of parabolic systems with delay and distributed parameters on the graph]. Vestnik of Saint Petersburg University. Applied Mathematics. Computer Science. Control Processes, 2017, vol. 13, iss. 2, pp. $209-224$. https://doi.org/10.21638/11701/spbu10.2017.207 (In Russian)

7. Provotorov V. V., Provotorova E. N. Optimal control of the linearized Navier-Stokes system in a netlike domain. Vestnik of Saint Petersburg University. Applied Mathematics. Computer Science. Control Processes, 2017, vol. 13, iss. 4, pp. 431-443. https://doi.org/10.21638/11702/spbu10.2017.409

8. Zhabko A. P., Nurtazina K. B., Provotorov V. V. About one approach to solving the inverse problem for parabolic equation. Vestnik of Saint Petersburg University. Applied Mathematics. Computer Science. Control Processes, 2019, vol. 15, iss. 3, pp. 323-336.

https://doi.org/10.21638/11702/spbu10.2019.303

9. Zhabko A. P., Provotorov V. V., Balaban O. R. Stabilization of weak solutions of parabolic systems with distributed parameters on the graph. Vestnik of Saint Petersburg University. Applied Mathematics. Computer Science. Control Processes, 2019, vol. 15, iss. 2, pp. 187-198.

https://doi.org/10.21638/11702/spbu10.2019.203

10. Zhabko A. P., Shindyapin A. I., Provotorov V. V. Stability of weak solutions of parabolic systems with distributed parameters on the graph. Vestnik of Saint Petersburg University. Applied Mathematics. Computer Science. Control Processes, 2019, vol. 15, iss. 4, pp. 457-471.

https://doi.org/10.21638/11702/spbu10.2019.404

11. Volkova A. S., Provotorov V. V. Generalized solutions and generalized eigenfunctions of boundary-value problems on a geometric graph. Russian Mathematics, 2014, vol. 58, no. 3, pp. 1-13. https://doi.org/10.3103/S1066369X14030013

12. Provotorov V. V. Eigenfunctions of the Sturm-Liouville problem on astar graph. Sbornik Mathematics, 2008, vol. 199, no. 10, pp. 1523-1545.

13. Provotorov V. V. Razlozenie po sobstvennym funkciyam zadachi Shturma-Liuvillya na grafepuchke [Expansion of eigenfunctions of Sturm-Liouville problem on astar graph]. Russian Mathematics, 2008, vol. 3, pp. 45-57. (In Russian)

14. Neuman J., Richtmyer R. D. A method for the numerical calculation of hydrodynamic shocks. Journal of Appl. Phys., 1950, vol. 21, no. 3, pp. 37-52.

15. Marchuk G. I. Metodi vichislitel'noi matematiki [Methods of computational mathematics]. Moscow, Nauka Publ., 1977, 456 p. (In Russian)

16. Provotorov V. V. Boundary control of a parabolic system with delay and distributed parameters on the graph. International Conference "Stability and Control Processes" in memory of V. I. Zubov (SCP). St. Petersburg, Russia, 2015, pp. 126-128.

17. Podvalny S. L., Podvalny E. S., Provotorov V. V. The controllability of parabolic systems with delay and distributed parameters on the graph. Procedia Computer Sciense, 2017, vol. 103, pp. 324-330.

18. Podvalny S. L., Provotorov V. V. Opredelenie startovoi funkcii v zadache nabludeniy parabolicheskoi sistemi na grafe [Determining the starting function in the task of observing the parabolic system with distributed parameters on the graph]. Vestnik of Voronezh State Technical University, 2014, vol. 10, no. 6, pp. 29-35. (In Russian)

19. Karelin V. V. Shtrafnye funkcii v zadache upravleniya processom nabludeniya [Penalty functions in the control problem of an observation process]. Vestnik of Saint Petersburg University. Series 10. Applied Mathematics. Computer Science. Control Processes, 2010, iss. 4, pp. 109-114. (In Russian)

20. Karelin V. V., Bure V. M., Svirkin M. V. Obobchennaja model rasprostranenija informacii v neprerivnom vremeni [The generalized model of information dissemination in continuous time]. Vestnik of Saint Petersburg University. Applied Mathematics. Computer Science. Control Processes, 2017, vol. 13, iss. 1, pp. 74-80. https://doi.org:10.21638/11701/spbu 10.2017.107 (In Russian) 
21. Alexandrova I. V., Zhabko A. P. A new LKF approach to stability analysis of linear systems with uncertain delays. Automatica, 2018, vol. 91, pp. 173-178.

22. Aleksandrov A., Aleksandrova E., Zhabko A. Asymptotic stability conditions for certain classes of mechanical systems with time delay. WSEAS Transactions on Systems and Control, 2014, vol. 9, pp. 388-397.

23. Aleksandrov A., Aleksandrova E., Zhabko A. Asymptotic stability conditions of solutions for nonlinear multiconnected time-delay systems. Circuits Systems and Signal Processing, 2016, vol. 35, no. 10, pp. 3531-3554.

24. Veremey E. I., Sotnikova M. V. Stabilizaciya plazmy na baze prognoza s ustoichivym lineinym priblizheniem [Plasma stabilization by prediction with stable linear approximation]. Vestnik of Saint Petersburg University. Series 10. Applied Mathematics. Computer Science. Control Processes, 2011, iss. 1, pp. 116-133. (In Russian)

25. Kamachkin A. M., Potapov D. K., Yevstafyeva V. V. Existence of subharmonic solutions to a hysteresis system with sinusoidal external influence. Electronic Journal of Differential Equations, 2017, no. 140 , pp. $1-10$.

26. Krasnov S., Sergeev S., Titov A., Zotova Y. Modelling of digital communication surfaces for products and services promotion. International Scientific Conference "Digital Transformation on Manufacturing, Infrastructure and Service”. St. Petersburg, Russia, 2019, vol. 497, pp. 012032.

https://doi.org/10.1088/1757-899X/497/1/012032

27. Borisoglebskaya L. N., Provotorova E. N., Sergeev S. M., Khudyakov A. P. Automated storage and retrieval system for Industry 4.0 concept. International Scientific Workshop "Advanced Technologies in Material Science, Mechanical and Automation Engineering", MIP: ENGINEERING-2019, IOP Conference. Series Mater. Sci. Eng., 2019, vol. 537, pp. 032036.

https://doi.org/10.1088/1757-899X/537/3/032036

Received: January 17, 2020.

Accepted: October 23, 2020.

Authors' information:

Vyacheslav V. Provotorov - Dr. Sci. in Physics and Mathematics, Professor; wwprov@mail.ru

Sergey M. Sergeev - PhD in Technics; sergeev2@yandex.ru

Hoang Van Nguyen - Postgraduate Student; fadded9x@gmail.com

\section{Счетная устойчивость слабого решения параболической дифференциально-разностной системы с распределенными параметрами на графе}

В. В. Провоторов ${ }^{1}$, С. М. Сергеев ${ }^{2}$, В. Н. Хоанг ${ }^{1}$

1 Воронежский государственный университет, Российская Федерация, 394006, Университетская пл., 1

2 Петербургский политехнический университет Петра Великого, Российская Федерация, 195251, Санкт-Петербург, ул. Политехническая, 29

Для цитирования: Provotorov V. V., Sergeev S. M., Hoang V. N. Countable stability of a weak solution of a parabolic differential-difference system with distributed parameters on the graph // Вестник Санкт-Петербургского университета. Прикладная математика. Информатика. Процессы управления. 2020. Т. 16. Вып. 4. С. 402-414.

https://doi.org/10.21638/11701/spbu10.2020.405

В работе предлагается аналог метода Е. Роте (метод полудискретизации по временной переменной) для построения сходящихся разностных схем при анализе устойчивости слабого решения начально-краевой задачи параболического типа с распределенными параметрами на графе в классе суммируемых функций. Этот метод позволяет исходную начально-краевую задачу привести к изучению краевой задачи в слабой постановке для уравнений эллиптического типа с распределенными параметрами на графе. В силу специфики указанного метода устойчивость слабого решения понимается в терминах 
спектрального критерия устойчивости (счетной устойчивости по Нейману), который устанавливает устойчивость решения по отношению к каждой гармонике обобщенного ряда Фурье слабого решения или отрезка этого ряда. Таким образом, выявлена еще одна возможность, кроме метода Фаэдо-Галеркина, построения приближений к искомому решению начально-краевой задачи, анализа его устойчивости и путь доказательства теоремы существования слабого решения исходной задачи. Используемый подход применим к отысканию достаточных условий устойчивости слабых решений других начально-краевых задач с более общими граничными условиями: в них эллиптические уравнения рассматриваются с краевыми условиями второго или третьего типа. Дальнейший анализ возможен при отыскании условий, при которых определяется устойчивость по Ляпунову. Изложенный подход можно использовать при анализе задач оптимального управления, а также задач стабилизации и устойчивости дифференциальных систем с запаздыванием. Представленный метод конечных разностей даст возможность проводить аппроксимацию состояний параболической системы, анализа их устойчивости, при численной реализации и алгоритмизации задач оптимального управления.

Ключевые слова: параболическая дифференциально-разностная система, распределенные параметры на графе, слабое решение, счетная устойчивость.

Контактная информация:

Провоторов Вячеслав Васильевич - д-р физ.-мат. наук, проф.; wwprov@mail.ru

Сергеев Сергей Михайлович - канд. техн. наук, доц.; sergeev2@yandex.ru

Хоанг Ван Нгуен - аспирант; fadded9x@gmail.com 